\title{
A man patient with ipsilateral breast metastasis from pulmonary adenocarcinoma
}

\author{
Ayperi Ozturk ${ }^{1 *}$, Derya Yenibertiz ${ }^{2}$, Zafer Aktas ${ }^{1}$, Aydın Y1maz $^{1}$ and Funda Demirag ${ }^{3}$ \\ ${ }^{1}$ Interventional Pulmonology Department, Ataturk Chest Diseases and Thoracic Surgery Training and Researsh Hospital, Ankara, Turkey \\ ${ }^{2}$ Pulmonary Medicine Department, Ataturk Chest Diseases and Thoracic Surgery Training and Researsh Hospital, Ankara, Turkey \\ ${ }^{3}$ Pathology Department, Ataturk Chest Diseases and Thoracic Surgery Training and Researsh Hospital, Ankara, Turkey
}

\begin{abstract}
Background: Breast metastasis from an extramammary primary tumor is rare, especially in men. Although primary breast cancer is the most common malignancy of adult females, metastasis of breast cancer is rare, with a reported frequency of $0.4-1.3 \%$ in clinical series.

Case presentation: We report a case of 63-year-old male patient with breast metastasis from lung adenocarcinoma. He was admitted with dyspnea and cough. As antral mass with irregular boundary was detected in posterior anterior chest radiography and thorax computed tomography (CT). A nodular lesion approximately $1 \mathrm{~cm}$ with low increased metabolic uptake (SUVmax:1.74) in left breast was found in positron emission tomography (PET/CT) in addition to mass in the left lung with multiple bone and mediastinal lymph node metastasis. Firstly, he underwent fiber optic bronchoscopy. An endobronchial lesion which obstructed the upper lobe of left lung was detected and biopsy was reported as adenocarcinoma. Secondly, biopsy was carried out from the left breast excluding for second primary cancer and pathology reported as metastasis of lung adenocarcinoma.
\end{abstract}

Conclusion: Herein, we want to emphasize breast metastasis in male patients with lung adenocarcinoma should be considered although low increased metabolic uptake levels.

\section{Introduction}

Breast carcinoma is the most common malignant tumors in women in the world. However, metastasis to the breast from extra mammary malignancies are rare, only accounts for $0.4-1.3 \%$ of all breast cancer $[1,2]$. According to the literature it is extremely rare for men [3]. Because of large fibrous tissue areas and poor blood supplying, breast is not suitable for metastasis. The metastasis to the breast from primary lung cancer is rather rare $(<0.5 \%)[4,5]$. It is also considerably rarer for male patients. It is very important to distinguish primary breast cancer from metastasis to breast, because the therapy offered would be different. In this report a case of male patient with lung adenocarcinoma metastasis to the ipsilateral breast was described. It is reported because of it's considerably rarity.

\section{Case report}

A 63 year-old, smoker, male patient presented to our hospital with dyspnea, dry cough and spread bone pains for 6 weeks' duration. $\mathrm{He}$ had not identified chronic medical diseases history and remarkable family medical history. In physical examination, respiratory sounds were reduced at base of left lung and a nodule palpated on left peri areolar area. On chest CT and X-ray, a central mass extending to left hilum by narrowing air column and obliterating left upper lobe bronchus with multiple nodules in both lung was revealed (Figure 1).

On PET/CT increased metabolic uptakes were determined in mass, multiple cervical and mediastinal lymph nodes with multiple lytic bone lesions. Also, a nodular lesion in retro areolar area of left breast, approximately $1 \mathrm{~cm}$, with low levels increased metabolic uptake (SUVmax:1.74) was determined (Figure 2).
Histopathological examination was recommended because findings described in left breast might be metastases or primary breast cancer. Primarily fiber optic bronchoscopy was performed. An endobronchial lesion that obstructed completely the upper lobe of left bronchus was revealed and biopsy was carried out. The pathology result was reported as non-small cell lung carcinoma compatible with adenocarcinoma by immunohistochemically. After marked by ultrasonography, an excisional biopsy was taken from the left breast. Focal mucin positivity

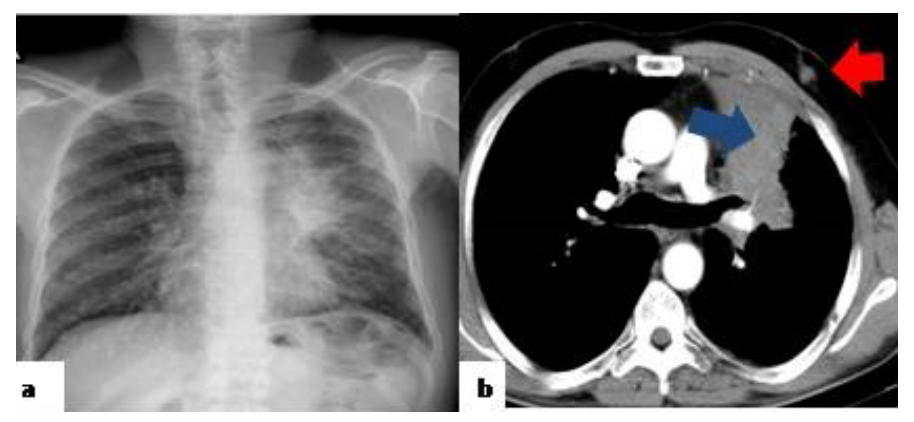

Figure 1. (a) A central mass located in the left hilum extending to upper and middle zone; (b) A nodular lesion was seen in left breast (red arrow) on chest CT in addition to the central hilar mass (blue arrow).

Correspondence to: Ayperi Ozturk, Interventional Pulmonary Department, Ataturk Chest Diseases and Thoracic Surgery Training and Research Hospital, Kecioren, Ankara, Turkey, Tel: 03125677142; E-mail: drayperi@yahoo.com

Key words: breast metastasis, lung cancer, adenocancer

Received: September 30, 2016; Accepted: December 28, 2016; Published: January 03, 2017 

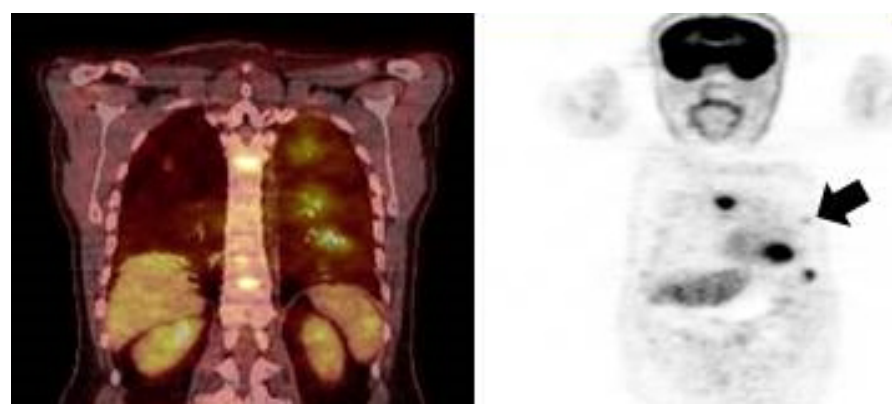

Figure 2. On PET/CT increased metabolic uptakes were detected in mass,multiple lytic bone lesions and also a nodular lesion (black arrow) in retroareolar area of left breast.
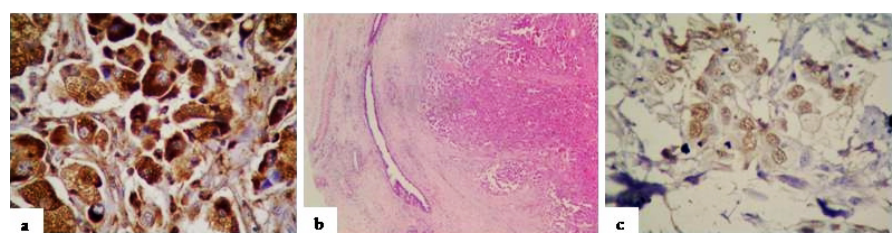

Figure 3. (a) Napsin A positivity in tumor cells (Napsin Ax400); (b) Infiltrating tumour cells in breast tissue (HEx40); (c) TTF-1 positivity in tumor cells (TTF-1x400).

and diffuse TTF -1 positivity were observed and $\mathrm{P} 63$ was negative in the tumor cells (Figure 3). Consequently it was reported as the metastasis of lung adenocarcinoma. He was defined as stage 4 of lung cancer and chemotherapy was planned for him. He died after 3 months of diagnosis.

\section{Discussion}

The lung cancer is the most common cancer in terms of both incidence and mortality in the world (1.6 million new cases per year and 1.378 million deaths) [6]. The most common metastatic organs of non-small cell lung cancer (NSCLC) are liver (33-40\%), adrenal glands (18-38\%), brain (15-43\%), bone (19-33\%), kidney (16-23\%) and abdominal lymph nodes (29\%). Metastasis of NSCLC to unusual sites is less frequent; especially metastasis to breast is extremely rare [7].

Primary breast carcinoma is the most prevalent malignant tumor among women. However, metastasis to breast from extramammary malignancies are extremely rare, the prevalence of such lesions ranges from $0.4-1.3 \%[1,2]$. The most common source of breast metastasis is the mammary itself [8]. Although metastasis to the mammary gland is uncommon from lung cancer especially among males, metastasis should be considered when a mammary mass does not exhibit the typical characteristics of breast cancer. A correct diagnosis of metastasis to mammary gland from lung cancer makes it possible to select the most appropriate clinical approaches and results. A review of the literature (1990-2010) revealed approximately 30 NSCLC case reports or studies as part of a series of secondary breast tumors. Twelve of these cases were classified as adenocarcinomas and eight of them were women [2]. It was remarkable that although the metabolic uptake of lesion was very low in PET CT (suv max:1.74), the pathology findings were compatible with metastasis of lung cancer. Lesions are generally apt to be multiple and bilateral in metastatic breast cancers [9]. On the contrary our case has a single and ipsilateral metastatic nodule. Breast cancer in males constitute the $1 \%$ of all breast cancers and metastatic of them in males is seen extremely rare. Survival in lung cancer with breast metastasis is usually poor that is average 3-6 months [5].

\section{Conclusion}

Herein, we were reported a single breast metastatic painless nodule with low metabolic uptake in PET-CT from ipsilateral pulmonary adenocarcinoma in a man patient. Although metastatic breast disease is seen rarely it should be considered that its treatment and prognosis differ greatly from primary breast cancer. We want to emphasize our case because of its importance in terms of gender and rarity.

\section{References}

1. Hajdu SI, Urban JA (1972) Cancers metastatic to the breast. Cancer 29: 1691-1696 [Crossref]

2. Klingen TA, Klaasen H, Aas H, Chen Y, Akslen LA (2009) Secondary breast cancer: a 5-year population-based study with review of the literature. APMIS 117: 762-767. [Crossref]

3. Bhagat P, Kline TS (1990) The male breast and malignant neoplasms. Diagnosis by aspiration biopsy cytology. Cancer 65: 2338-2341. [Crossref]

4. Ramar K, Pervez H, Potti A, Mehdi S (2003) Breast metastasis from non-small-cell lung carcinoma. Med Oncol 20: 181-184. [Crossref]

5. Sneige N, Zachariah S, Fanning TV, Dekmezian RH, Ordóñez NG (1989) Fine-needle aspiration cytology of metastatic neoplasms in the breast. Am J Clin Pathol 92: 27-35. [Crossref]

6. Ferlay J, Shin HR, Bray F, Globocan (2008) Cancer Incidence and Mortality Worldwide IARC CancerBase.

7. Quint LE, Tummala S, Brisson LJ, Francis IR, Krupnick AS, et al. (1996) Distribution of distant metastases from newly diagnosed non-small cell lung cancer. Ann Thorac Surg 62: 246-250. [Crossref]

8. McIntosh IH, Hooper AA, Millis RR, Greening WP (1976) Metastatic carcinoma within the breast. Clin Oncol 2: 393-401. [Crossref]

9. Akçay MN (2002) Metastatic disease in the breast. Breast 11: 526-528. [Crossref]

Copyright: (C2017 Ozturk A. This is an open-access article distributed under the terms of the Creative Commons Attribution License, which permits unrestricted use, distribution, and reproduction in any medium, provided the original author and source are credited. 